\title{
Acquired tastes: establishing food (dis-)likes by flavour-flavour learning
}

Citation for published version (APA):

Havermans, R. C., \& Jansen, A. T. M. (2011). Acquired tastes: establishing food (dis-)likes by flavourflavour learning. In V. R. Preedy, R. R. Watson, \& C. R. Martin (Eds.), Handbook of behavior, food and nutrition (pp. 73-84). Springer. https://doi.org/10.1007/978-0-387-92271-3_6

Document status and date:

Published: 01/01/2011

DOI:

10.1007/978-0-387-92271-3_6

Document Version:

Publisher's PDF, also known as Version of record

Document license:

Taverne

Please check the document version of this publication:

- A submitted manuscript is the version of the article upon submission and before peer-review. There can be important differences between the submitted version and the official published version of record.

People interested in the research are advised to contact the author for the final version of the publication, or visit the DOI to the publisher's website.

- The final author version and the galley proof are versions of the publication after peer review.

- The final published version features the final layout of the paper including the volume, issue and page numbers.

Link to publication

\footnotetext{
General rights rights.

- You may freely distribute the URL identifying the publication in the public portal. please follow below link for the End User Agreement:

www.umlib.nl/taverne-license

Take down policy

If you believe that this document breaches copyright please contact us at:

repository@maastrichtuniversity.nl

providing details and we will investigate your claim.
}

Copyright and moral rights for the publications made accessible in the public portal are retained by the authors and/or other copyright owners and it is a condition of accessing publications that users recognise and abide by the legal requirements associated with these

- Users may download and print one copy of any publication from the public portal for the purpose of private study or research.

- You may not further distribute the material or use it for any profit-making activity or commercial gain

If the publication is distributed under the terms of Article $25 \mathrm{fa}$ of the Dutch Copyright Act, indicated by the "Taverne" license above, 


\title{
Chapter 6 \\ Acquired Tastes: Establishing Food (Dis-)Likes by Flavour-Flavour Learning
}

\author{
Remco C. Havermans and Anita Jansen
}

\begin{abstract}
Abbreviations
ANC Amygdalar nuclear complex

BMI Body mass index

CS Conditioned stimulus

OFC Orbitofrontal cortex

PDD Pervasive developmental disorder

UCS Unconditioned stimulus
\end{abstract}

\subsection{Introduction}

It is a truism that eating behaviour (i.e. food choice and food intake) is determined by many different factors. Nonetheless, within the normal physiological boundaries of satiety and hunger one may argue that people simply eat what they like and avoid foods they do not like (Eertmans et al. 2001). Such hedonic eating behaviour is particularly apparent in children. For example, in the early twentieth century, most Dutch children (in addition to children in many other countries) still received a daily spoonful of cod liver oil before bedtime. Many of these individuals, now adults, still shiver at the memory of the often rancid taste of cod liver oil. However, there was good reason to subject children to this cod liver oil ordeal, as this oil was known to somehow prevent rickets (or rachitis; the softening of bones misshaping knees, wrists, and ankles). It wasn't until the 1930s that it was recognised that rickets is caused by vitamin D deficiency and that cod liver oil is rich in such vitamin D. This knowledge eventually allowed for the development of vitamin D supplementation and with it the standard practise of administering children cod liver oil dissipated. One will cease the consumption of aversive tastes when there is no pressing need for the consumption of such tastes.

People are born with a preference for sweet tastes and an aversion against bitter tastes, but more specific flavour preferences are developed during later childhood. Specific food likes and dislikes can differ between individuals and this suggests that these preferences are acquired through personal experience with certain flavours. In other words, one acquires a (dis)taste for certain foods by trying out these foods (Capaldi and Vandenbos 1991). How then does this work exactly? A prominent form

R.C. Havermans $(\bowtie)$

Department of Clinical Psychological Science, Maastricht University, Maastricht, 6200 MD, The Netherlands

e-mail:r.havermans@maastrichtuniversity.nl 
of such purported experiential learning involves Pavlovian conditioning, the learning of an association between a neutral conditioned stimulus (CS) (e.g. a flavour) and a biologically relevant unconditioned stimulus (UCS). In the case of conditioned taste aversion learning, the UCS usually comprises some degree of gastrointestinal discomfort. By pairing a specific flavour with such discomfort, one comes to associate the flavour with the discomfort and this then leads to future avoidance of the flavour (Pelchat and Rozin 1982). Pavlovian conditioning has then endowed the flavour CS a signalling function, it 'predicts' internal malaise (the UCS). Likewise, it was found in animals that a taste preference is conditioned for flavours paired with the recovery of illness (Green and Garcia 1971).

Another way of conditioning a food preference was demonstrated by Holman (1975). In one of his experiments, he gave rats on alternate days either a banana- or almond-flavoured mash. To this mash, he added saccharin to make it taste sweet. Rats, like humans, have an innate preference for sweet tastes. Holman varied the concentration of the saccharin of the different mashes. Rats were divided into two groups: A and B. Group A received 60 min access to the almond paired with concentrated saccharin and banana paired with diluted saccharin solution. For group B, the flavour to saccharin concentration (concentrated versus diluted) assignment was reversed. At test, the rats received $30 \mathrm{~min}$ access to $40 \mathrm{~mL}$ of both flavours now with an equal saccharin concentration. The rats showed a clear preference for the flavour previously paired with the concentrated saccharin. Figure 6.1 displays an illustration of the procedure, design, and results of this experiment. On the basis of these and similar findings, Holman concluded that the apparent reinforcing effect of saccharin is the hedonic quality of its sweet flavour. This form of learning has thus been termed flavour-flavour learning as the apparent

\section{0-day training phase:}
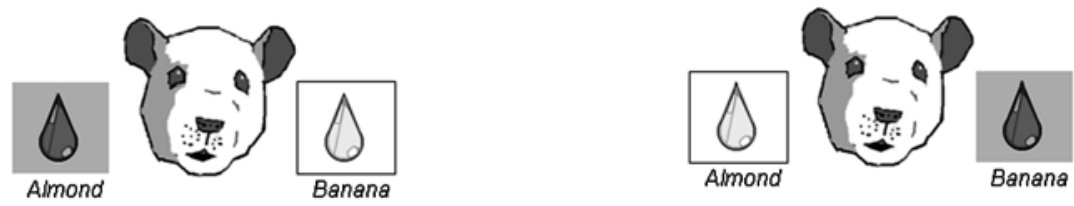

GROUP A

GROUP B

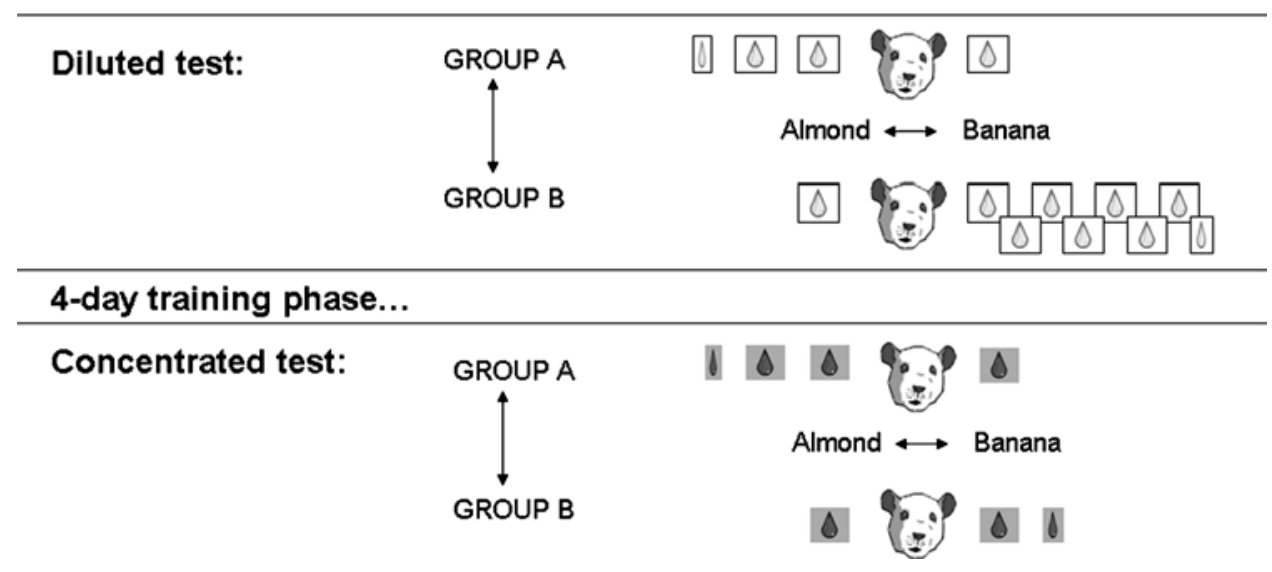

Fig.6.1 Design, procedure and results of Eric Holman's (1975) experiment on flavour-flavour learning. Eric Holman (1975; Experiment 2) gave rats during a 20-day training period one flavour paired with concentrated saccharin on even days and another flavour paired with diluted saccharin on uneven days. On a first test, rats were given simultaneous access to both flavours, now both with diluted saccharin. Rats drank much more of the flavour previously paired with the concentrated saccharin. On a second test, after another 4-day period of training, the same pattern of results was obtained when both flavours were now presented with concentrated saccharin 
Table 6.1 Key facts concerning flavour-flavour learning and its applications

A neutral flavour becomes more liked or less liked after having been paired with, respectively, an already liked or disliked flavour

Children can come to better like the flavour of fruits and vegetables through flavour-flavour learning

shift in flavour preference arises from the acquisition of an association between two flavours: a neutral flavour (e.g. almond) and an already liked flavour (e.g. the sweet taste of concentrated saccharin) (Fanselow and Birk 1982; Myers and Sclafani 2006).

Some researchers argue that a flavour-flavour association is qualitatively different from a preference arising from flavour-consequence learning. As the latter form of association is recognised as the result of Pavlovian conditioning, this implies that flavour-flavour learning may not be considered as a form of Pavlovian associative learning (Hermans et al. 2002) and this gives rise to the question what mechanism then underlies flavour-flavour learning. Other questions raised and discussed in the present chapter concern the generality of flavour-flavour learning, its neurological underpinnings and its application to promoting the development of healthy dietary habits in children (Table 6.1).

\subsection{What is Flavour-Flavour learning?}

Flavour-flavour learning comprises the transfer of affect to a neutral flavour CS by pairing that particular flavour with another already liked or disliked flavour UCS. The established shift in liking is always in the direction of the affective value of the evaluative UCS. This is why flavour-flavour learning is generally regarded as a form of evaluative conditioning. But what exactly is evaluative conditioning?

\subsubsection{Evaluative Conditioning}

In a particular study, Levey and Martin (1975) had participants categorise pictures of paintings as liked, neutral, or disliked. Subsequently, the participants received exposure to several neutral pictures paired with other liked pictures, or neutral pictures, or disliked pictures. At test, participants had to evaluate all pictures and it was found that they now rated the neutral pictures that had previously been paired with the disliked pictures more negatively and the neutral pictures that had been paired with the liked pictures as more positive. Martin and Levey (1978) termed this transfer of affect to an originally neutral stimulus due to pairings of this stimulus with another affective (positive or negative) stimulus evaluative conditioning.

Procedurally, evaluative conditioning is very similar to Pavlovian conditioning. With evaluative conditioning, the neutral stimulus is usually referred to as the CS and the affective stimulus as the UCS. Pairing these stimuli should then lead to the formation of an association between these two stimuli, allowing for the transfer of affect from the UCS to the CS. Despite the procedural similarity there are notable discrepancies between evaluative conditioning and other more typical Pavlovian conditioning paradigms such as fear conditioning. In the case of fear conditioning, the CS, a neutral stimulus (e.g. a tone or a picture), is paired with aversive stimulation, such as the administration of an electric shock or a very loud noise. Hermans et al. (2002) exposed participants to such a procedure, pairing pictures of faces (the CSs) with electrocutaneous stimulation (the UCS; i.e. an aversive electric shock). The participant learned to anticipate this adverse stimulation that was reflected by a strong expectation of the UCS when presented with the CS previously paired with the UCS. Hermans and colleagues also showed that participants came to dislike the CSs that had been paired with the 
UCS, indicating evaluative conditioning. UCS expectations extinguish easily with non-reinforced exposures to the CS (Dibbets et al. 2008), but an acquired evaluative shift is highly resistant to such an extinction treatment (De Houwer et al. 2000).

Pavlovian conditioning can be described in terms of signal learning; one learns to recognise the CS as a signal for the UCS, and hence, when exposed to the CS, one expects the UCS. No such learning is required in case of evaluative conditioning; the CS then merely has to refer to the UCS (see also De Houwer et al. 2000).

In line with the reasoning that evaluative conditioning reflects some form of referential learning, Havermans and Jansen (2007a) argue that evaluative conditioning more specifically reflects a stimulus generalisation process. Within Pavlovian conditioning, it is well known that an acquired associative strength can generalise from one CS to other CSs. The extent of transfer of associative value is determined by the degree of similarity between the CS and the novel stimulus (Pearce 2002). According to Havermans and Jansen, such transfer is probably not limited to associative value. Indeed, it may also comprise the transfer of other relevant stimulus characteristics, such as affective value. This then means that pairing a neutral CS with an evaluative UCS merely provides one the opportunity for determining (or just passively experiencing) the similarity between the two stimuli. If there is some degree of stimulus similarity, and if this similarity is somehow noted, this may be enough to induce the transfer of affect from the UCS to the CS (Davey 1994; Field and Davey 1999). Figure 6.2 represents the stimulus generalisation model of evaluative conditioning as outlined by Havermans and Jansen.

\subsubsection{The Flavour-Flavour Paradigm}

Evaluative conditioning is not limited to the transfer of affect between visual stimuli such as the pictures of paintings. Indeed, it was soon recognised that flavour-flavour learning can also be understood in terms of evaluative conditioning. In fact the flavour-flavour paradigm is recognised as one of the more robust forms of evaluative conditioning (Field et al. 2008).

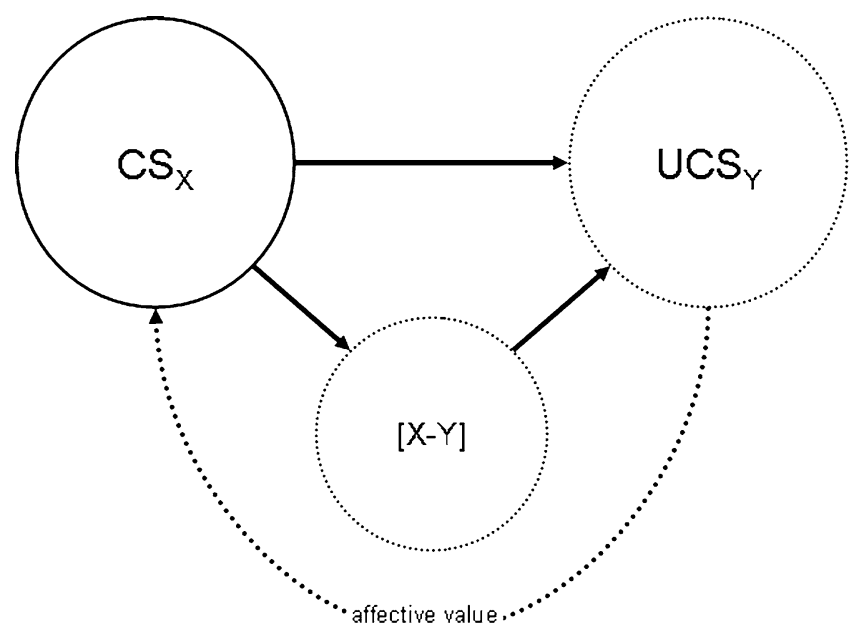

Fig.6.2 A stimulus generalisation model of evaluative conditioning. Havermans and Jansen (2007a) argue that when a neutral CS X is paired with an affective UCS Y a configural X-Y representation is formed in memory. When subsequently $\mathrm{X}$ is presented, the representation of the UCS Y will be activated directly through its similarity with $\mathrm{X}$ and indirectly through the X-Y configural representation. The degree to which the representation of $\mathrm{Y}$ is activated determines the extent of affective value being transferred from Y to CS X 
As described above, Eric Holman (1975) tested whether a rat's flavour preference could be influenced by the sweetness of saccharin associated with the flavour. It could and such flavour-flavour learning is not limited to rats; it has also been demonstrated in humans. Baeyens et al. (1995) found that pairing a flavour with the aversive taste of polysorbate-20 (the emulsifier Tween) led to decreased liking of that particular flavour (see also Baeyens et al. 1990, 1996, 1998a, b). These researchers, however, did not find evidence of positive flavour-flavour learning with pairings of a specific neutral flavour with a sweet taste. This may mean that negative flavour-flavour learning is more easily established than positive flavour-flavour learning, but the failure to induce positive flavour-flavour learning could also be attributed to the fact that the participants only moderately liked the sweet taste. It was already shown that it certainly is not impossible to induce positive flavour-flavour learning. Zellner et al. (1983) had students drink different flavours of tea. Some of these teas had to be tasted several times with sweet-tasting sucrose. At test, all participants again had to taste and evaluate the different teas, now left unsweetened, and the participants clearly and specifically liked the previously sweetened teas better. Yeomans et al. (2008) similarly found evidence of positive flavour-flavour learning when a specific flavour of dessert was paired with the sweet taste of either sucrose or aspartame. To ensure that the sweet taste (the flavour UCS) was well liked, Yeomans took care to only select self-identified sweet likers for participation in their study.

Interestingly, Brunstrom et al. (2001) found that unrestrained eaters showed enhanced preference for drinks most often paired with a sweet reward (e.g. chocolate chips, puffed rice or raisins), but this was not found among restrained eaters, suggesting that dietary restraint somehow devalues the sweet reward. This is precisely what Brunstrom et al. (2005) found in a series of two experiments. In one of these experiments, Brunstrom and colleagues paired different fruit juices of with a sweet reward (i.e. chocolate chips). One of the juices was paired on just $10 \%$ of trials with the sweet and another juice was paired $90 \%$ of the trials with the sweet reward. Unrestrained eaters came to prefer the $90 \%$ paired picture, but the restrained eaters came to prefer the less-often paired pictures. Brunstrom and colleagues thus argued that negative beliefs and attitudes regarding the UCS devalue the UCS and within restrained eaters may in fact function as an aversive stimulus, thus promoting the acquisition of a dislike. In a more recent study, however, Brunstrom and Fletcher (2008) failed to replicate this effect of dietary restraint on flavour-flavour learning, but instead found an effect of hunger state. When pairing tea with a non-caloric sweetener, only hungry participants came to like the flavour of this particular tea relative to other unsweetened teas. Similarly, Mobini et al. (2007) found that pairing a peach-flavoured tea with another sucrose drink, increased liking for the tea particularly when participants had been trained and tested hungry. Further, Yeomans and Mobini (2006) demonstrated that increased liking for odours paired with a sweet sucrose UCS was apparent only when participants were hungry. One may argue that hunger increases attention and liking for caloric cues, such as a sweet taste that generally signals carbohydrate energy (e.g. as in the case of sucrose, fructose and glucose), hence increasing the salience of the flavour UCS allowing for larger transfer of affective value to the CS flavour (see Fig. 6.3).

\subsubsection{Neural Correlates of Flavour-Flavour Learning}

Cues associated with a certain food UCS can come to affect subsequent food choice and food intake. The brain structures known to be involved in the expression of cue-induced food selection and acceptance, such as the hypothalamus, amygdala and OFC probably also play a role in the associative acquisition of food likes and dislikes (see Holland and Petrovich 2005). Indeed, although many brain areas are activated with exposure to the sight, smell and taste of food, studies on the evaluation of food stimuli ubiquitously point to the specific involvement of the amygdala, the OFC and the insula. 


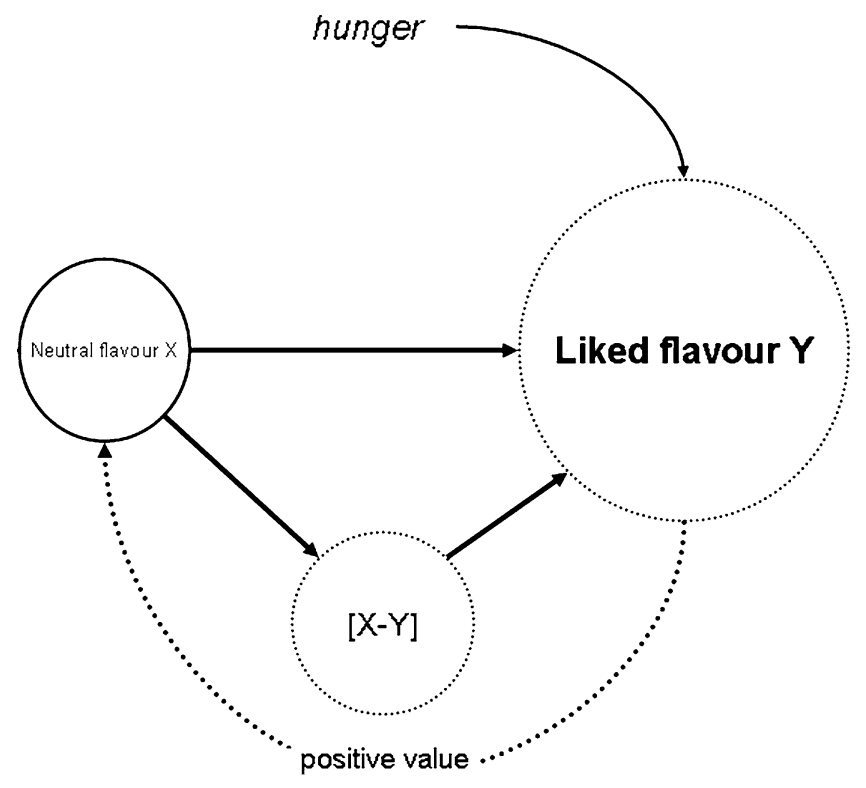

Fig. 6.3 Flavour-flavour learning as stimulus generalisationIn terms of the stimulus generalisation model of evaluative conditioning as put forward by Havermans and Jansen (2007a), pairing a neutral flavour X with an already liked flavour Y, leads to the formation of a configural X-Y representation in memory. Subsequent presentation of X alone then leads to the activation of the configural X-Y unit and the representation of flavour Y. If one is hungry, the salience of the representation of $\mathrm{Y}$ is hypothetically bigger and allows for more transfer of affective value to flavour $\mathrm{X}$

With oral taste neurons projecting directly to the insula, activation of this area has been associated with representations of taste intensity and quality (e.g. texture, taste intensity, bitterness, sweetness, sourness or saltiness) and is thus referred to as the primary gustatory cortex (Small et al. 1999; De Araujo and Rolls 2004). Adjacent to this area, the OFC is involved in representations of the purported acquired valence of food cues (e.g. the pleasure derived from the sight, smell and taste of food). This region, therefore, has been termed the secondary taste cortex. Rolls and colleagues showed that decreasing the subjective pleasure derived from eating a specific food item through repeated exposure to that food leads to a corresponding decrease in the activation within the OFC when presented with that specific food item (see Rolls 2000).

The amygdala is recognised to be activated by both pleasurable and aversive food cues (O'Doherty et al. 2001) and thus appears to respond nonspecifically to any valenced food stimulus. Recent research suggests that such activation of the amygdala requires deliberate and attentive processing of the presented food stimulus (Siep et al. 2009).

Considering the presumed involvement of the amygdala in the conditioning of likes and dislikes, Coppens et al. (2006) examined whether patients with a unilateral section of the temporal lobe (which includes the amygdala) exhibit impaired flavour-flavour learning as compared to a control. Participants received two flavours, one of which was served with the addition of Tween. The researchers hypothesised that given the fact that even unilateral damage to the amygdala (i.e. the ANC) attenuates fear conditioning; such damage would also disturb evaluative conditioning. However, all participants demonstrated clear negative flavour-flavour learning, acquiring a dislike for the Tweenpaired flavour CS relative to the unpaired CS. The authors correctly point out that this does not mean that the amygdala does not play any role in the acquisition of food likes and dislikes as all the patients included in the study had only unilateral damage to the ANC. Clearly, more research is needed to determine the exact neurological underpinnings of flavour-flavour learning. 


\subsection{Applying Flavour-Flavour Learning to Increase Liking for Vegetables}

Overweight $\left(\mathrm{BMI}>25 \mathrm{~kg} / \mathrm{m}^{2}\right)$ is a rapidly increasing worldwide health problem. Especially obesity (i.e. severe overweight; BMI > 30) poses several health risks, such as coronary heart diseases and type II diabetes. It is estimated that currently in the USA approximately $25 \%$ of total health care costs are associated with obesity, a percentage representing billions of dollars (Levi et al. 2009). Currently, more than two-thirds of the US population is overweight or obese. Table 6.2 displays the present top five states with the highest obesity rates of the USA.

The number of overweight children has also increased dramatically in the past few decades. The health risks associated with obesity at a young age are less dire, but it is more difficult to attain a normal weight if one has been obese since childhood. Moreover, the health risks for obese adults who have been obese since their childhood are greater than for people who became obese in later adulthood (see e.g. Visscher et al. 2002).

Overweight and obesity are the result of a positive energy balance; more energy is consumed than expended. Particularly excessive caloric intake is now thought to have contributed to the steep rise in the incidence of obesity (Swinburn et al. 2009). Healthier eating, that is, consuming less high-calorie products should lower the prevalence of overweight. Indeed, Raynor and Epstein (2001) demonstrated that whereas consuming many different snacks is related to obesity, the consumption of a large variety of fruits and vegetables is associated with lean body weight. Therefore, getting people (especially children) to eat ample amounts of fruits and vegetables may prove to be an effective strategy in curbing the present obesity epidemic.

Recently, we reasoned that flavour-flavour learning might be a powerful technique to increase children's liking of vegetables, and hence their consumption of vegetables. To test whether such flavour-flavour learning actually increases children's liking of vegetables, we conducted an experiment. In this experiment 4- to 6-year-old children evaluated and rank ordered six different vegetables. Next, they were instructed to repeatedly consume small amounts of two of the six specific vegetables. These two flavours served as the flavour CSs and one of the two vegetables was now sweetened with glucose. After this repeated exposure procedure, all children again were instructed to evaluate and rank order the six vegetables. At this posttest, the children now specifically ranked the previously sweetened vegetable as better liked than before (Havermans and Jansen 2007b; see Fig. 6.4).

This positive flavour-flavour learning effect was also demonstrated in a more recent study by Capaldi and Privitera (2008). In a first experiment they had 2- to 5-year-old children repeatedly taste grapefruit juice mixed with the sweet taste of sucrose. This led to increased liking of unsweetened grapefruit juice. Moreover, this positive shift in liking proved stable for weeks. In a second experiment, undergraduate students were presented with several occasions in which they were instructed to consume one small stalk of cauliflower and another stalk of broccoli. One of the two vegetables

Table 6.2 Current obesity rates in the USA

\begin{tabular}{lll}
\hline & State & Obesity rate $(\%)$ \\
\hline 1 & Mississippi & 32.5 \\
2 & Alabama & 31.2 \\
3 & West Virginia & 31.1 \\
4 & Tennessee & 30.2 \\
5 & South Carolina & 29.7 \\
\hline
\end{tabular}

Top five states with the most obese people in the USA, as reported by the Trust for America's Health in their sixth annual issue report (Levi et al. 2009) on the obesity epidemic in the USA 


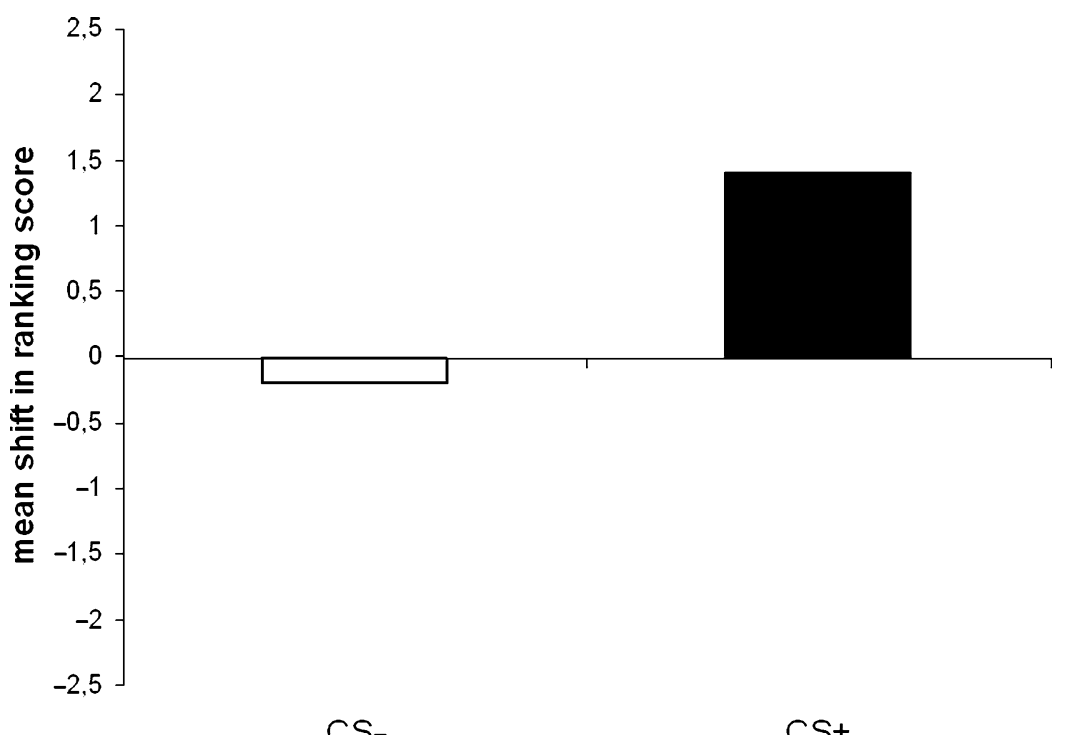

Fig. 6.4 Children's changes in hedonic ranking of vegetables as the result of flavour-flavour learning. Mean shift in ranking score (from pretest to posttest) for the CS paired with glucose (CS+) compared with the shift in ranking for the unpaired CS (CS-), as demonstrated by Havermans and Jansen (2007b) in the conditioning of vegetable flavour preferences in children

would be sweetened by having it dipped in sugar water. The assignment of vegetable to sugar water was counterbalanced between participants. Capaldi and Privitera found that the pairings of either cauliflower or broccoli with sugar increased liking of the taste of these vegetables.

In sum, the results from the studies discussed above suggest that the flavour-flavour learning paradigm can be applied to increase children's liking of fruits and vegetables. Importantly, this can be achieved even when the taste of the CS is initially disliked (e.g. the bitter taste of grapefruit), plus the achieved hedonic shift appears to be stable over a longer term.

\subsection{Applications to Other Areas of Health and Disease}

Children can develop strong food preferences and as a result may be particularly finicky about having to eat certain foods (Dovey et al. 2008). When such picky eating becomes a longer term habit of eating a very limited variety of food items, this food selectivity can form a serious health risk. One way to treat such food selectivity is through mere exposure. Williams et al. (2008), for example, used this method in six children being treated for extreme food selectivity. One case concerned a young girl diagnosed with autism who during treatment was exposed regularly to foods presented in meals and taste sessions. Meals would contain three table spoons of about three different foods (fruits, vegetables, meat, starch or dairy product), and taste sessions were used to introduce the child to a specific novel food. This mere exposure worked very well. She learned to accept and eat many different foods. Of the 49 different novel foods she learned to eat, she still ate 47 at 3 months after treatment.

Mere exposure thus seems to be a viable method to treat food selectivity. However, flavour-flavour learning may be even more powerful in the treatment of such food selectivity. Compared with a mere 
exposure procedure, flavour-flavour learning requires relatively few learning trials. Such flavour-flavour learning may involve the pairing of a novel or nonpreferred food with an already liked food. Furthermore, this pairing should be simultaneous, that is, the two foods (liked and disliked) should be presented together, rather than sequentially, as was shown by Holman (1975) in his rat studies. In one experiment, Holman found that pairing a flavour CS (CS+; cinnamon or wintergreen) with saccharin induced a flavour preference relative to another unpaired flavour (CS-; cinnamon when CS+ was wintergreen, and vice versa). Holman, however, failed to induce a flavour preference for the $\mathrm{CS}+$ in a following experiment when he inserted a 30 min interval between the consumption of the CS+ and the ingestion of a saccharin solution. The procedure, design and results of these experiments are illustrated in Fig. 6.5.

Piazza et al. (2002) compared simultaneous and sequential pairings of non-preferred foods with preferred foods in three children treated for food selectivity. One 11-year-old girl diagnosed with PDD ate lettuce with salad dressing and a few other creamy foods, but not much else. She received exposure to foods from different food groups (fruits and vegetables, starches and protein-rich foods) and these foods were paired with salad dressing. One group of foods (A) was always presented simultaneously with the salad dressing. Another group of foods (B) was paired sequentially with the dressing. The girl would only come to eat the foods from group A, not the foods from group B, corroborating the notion and previous findings that simultaneous pairings are superior in inducing an evaluative shift. Similar findings were reported for the other two cases in this study. It thus seems that food selectivity can be treated by means of evaluative conditioning, but note that the researchers did

\section{Experiment 3}
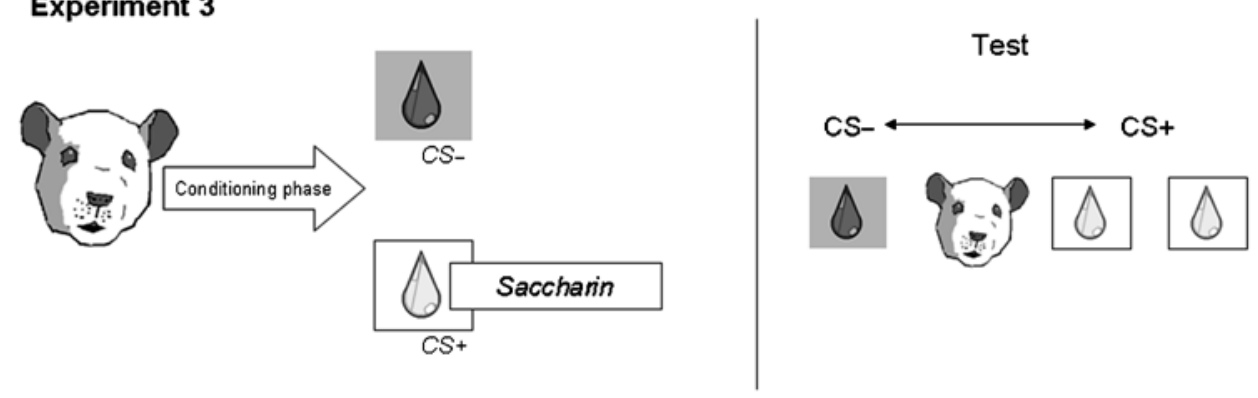

\section{Experiment 4}

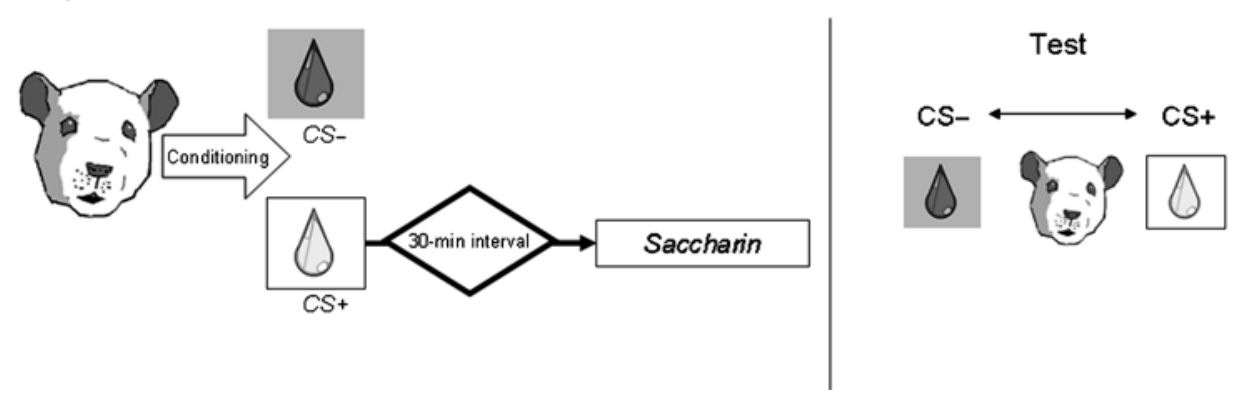

Fig.6.5 Holman experiments indicating that only simultaneous CS-UCS pairings induce a shift in CS flavour preference. An illustration of the procedure, design and main results of two experiments by Holman (1975; Experiments 3 and 4). Both experiments comprised comparing a shift in liking/preference between a CS+ paired with saccharin (the UCS) and another explicitly unpaired CS flavour (i.e. CS-). At test, the animals received the opportunity to drink from both (now unsweetened) flavours. The tests results from both experiments taken together clearly demonstrate that simultaneous (Experiment 3) but not sequential pairing (Experiment 4) of the CS+ with saccharin induces a flavour preference relative to CS- 
not present the 'non-preferred' foods separately without the unconditioned flavour after the repeated pairings. This makes it impossible to assess any positive shift in liking of the flavour of the nonpreferred food itself. Furthermore, as the authors themselves note, they did not conduct a follow-up test. Whether flavour-flavour learning is indeed beneficial and perhaps even superior to a mere exposure procedure in the treatment of food selectivity thus requires further empirical validation.

\subsection{Conclusion}

Evaluative conditioning is the transfer of affective value from an affective stimulus to another stimulus, due to pairing of the latter stimulus with the affective stimulus. As such, flavour-flavour learning - the transfer of affective value to a flavour being paired with an already liked/disliked flavour - can be regarded as a specific instance of evaluative conditioning.

Flavour-flavour learning is a robust form of evaluative conditioning and has been demonstrated in both animals and humans. Humans appear especially sensitive to the reinforcing sweet taste of sugar (Yeomans et al. 2008). The reason for this is unknown, but recent research suggests that humans possess orosensory receptors that specifically function to detect the presence of carbohydrates (apart from sweet taste). Oral maltodextrin (not sweet) and glucose (sweet) both directly activated brain regions known to be involved in the processing of the reward value of food, such as the insula, OFC and striatum (Chambers et al. 2009). One may hypothesise then that flavour-flavour learning in humans is probably much more effective when using some form of sugar and may even be evident when using non-sweet carbohydrates as UCS.

Flavour-flavour learning has proven to be a powerful technique to change someone's preference for a flavour and hence food. It is rapid and requires relatively little experience with the flavours themselves. In terms of nutrition and health, it has been shown that it can be applied to increase children's liking of fruits and vegetables even when the foods are initially disliked (Capaldi and Privitera 2008). However, whether the established positive change in hedonics also leads to a corresponding positive change in behaviour is an effect that is predicted but as of yet has not been examined empirically. The full benefits of flavour-flavour learning to nutrition thus still wait to be examined.

\section{Summary Points}

- Food choice and intake can be understood in terms of hedonic behaviour; that is, one prefers consuming foods one likes and tries to avoid having to eat foods one does not like.

- Food likes and dislikes are mostly acquired through direct experience with food.

- Flavour-flavour learning, a form of evaluative conditioning, comprises the transfer of affect (positive or negative) to a flavour by pairing that particular flavour with another already liked or disliked flavour.

- In humans, positive flavour-flavour learning seems to be mediated by hunger state.

- The amygdala is thought to play a critical role in the acquisition of flavour (dis)likes through flavour-flavour learning.

- Flavour-flavour learning can be applied to increase children's liking of fruits and vegetables and may be a beneficial technique in the treatment of severe cases of food selectivity. 


\section{Key Terms}

Evaluative conditioning: A learning paradigm in which pairing a CS with a positive UCS results in a positive shift in liking for the initially neutral CS, whereas conversely, pairing such a stimulus with a negative UCS results in a negative shift in liking.

Flavour-flavour learning: A form of evaluative conditioning that allows for the learning of flavour preferences by pairing a flavour with an already liked flavour, such as the sweet taste of saccharin or sugar.

Food selectivity: Feeding disorder diagnosed in infants or children when the child is not eating adequately and the insufficient food intake cannot be attributed to any specific medical condition.

Hedonic eating behaviour: The principle that anticipated and derived pleasure guide food choice and food intake, respectively.

Pavlovian conditioning: The learning of a response to a CS due to its pairings with a biologically relevant UCS. This conditioned response typically reflects the anticipation of the UCS.

Stimulus generalisation: Transfer of prominent qualities of one stimulus - such as its associative and affective value - to another stimulus.

\section{References}

Baeyens F, Eelen P, Van den Bergh O, Crombez G. Learn Motiv. 1990;21:434-55.

Baeyens F, Crombez G, Hendrickx H, Eelen P. Learn Motiv. 1995;26:141-60.

Baeyens F, Crombez G, De Houwer J, Eelen P. Learn Motiv. 1996;27:200-41.

Baeyens F, Hendrickx H, Crombez G, Hermans D. Appetite. 1998a;31:185-204.

Baeyens F, Vanhouche W, Crombez G, Eelen P. Psychologica Belgica. 1998b;38:83-108.

Brunstrom JM, Fletcher HZ. Physiol Behav. 2008;93:13-9.

Brunstrom JM, Downes CR, Higgs S. Appetite. 2001;37:197-206.

Brunstrom JM, Higgs S, Mitchell GL. Physiol Behav. 2005;85:524-35.

Capaldi ED, Privitera GJ. Appetite. 2008;50:139-45.

Capaldi ED, VandenBos GR. Hosp Community Psychiatry. 1991;42:787-9.

Chambers ES, Bridge MW, Jones DA. J Physiol. 2009;587:1779-94.

Coppens E, Vansteenwegen D, Baeyens F, Vandenbulcke M, van Paesschen W, Eelen P. Neuropsychologia. 2006;44:840-3.

Davey GCL. A reply to Martin and Levey (1994). Behav Res Ther. 1994;32:307-10.

De Araujo IE, Rolls ET. J Neurosci. 2004;24:3086-93.

De Houwer J, Thomas S, Baeyens F. Psych Bull. 2000;127:853-69.

Dibbets P, Havermans R, Arntz A. Behav Res Ther. 2008;46:1070-7.

Dovey TM, Staples PA, Gibson EL, Halford JCG. Appetite. 2008;50:181-93.

Eertmans A, Baeyens F, Van den Bergh O. Health Educ Res. 2001;16:443-56.

Fanselow MS, Birk J. Anim Learn Behav. 1982;10:223-8.

Field AP, Davey GCL. J Exp Psychol Anim Behav Proc. 1999;25:211-24.

Field AP, Lascelles KRR, Lester KJ, Askew C, Davey GCL. Neth J Psychol. 2008;64:46-64.

Green KF, Garcia J. Science. 1971;173:749-51.

Havermans RC, Jansen A. Neth J Psychol. 2007a;63:38-49.

Havermans RC, Jansen A. Appetite. 2007b;48:259-62.

Hermans D, Vansteenwegen D, Crombez G, Baeyens F, Eelen P. Behav Res Ther. 2002;40:217-34.

Holland PC, Petrovich GD. Physiol Behav. 2005;86:747-61.

Holman EW. Learn Motiv. 1975;6:91-100.

Levey AB, Martin I. Behav Res Ther. 1975;4:205-7.

Levi J, Vinter S, Richardson L, St Laurent R, Segal L. Trust for America's Health \& Robert Wood Johnson Foundation; 2009. 
Martin I, Levey AB. Adv Behav Res Ther. 1978;1:57-102.

Mobini S, Chambers LC, Yeomans MR. Appetite. 2007;48:20-8.

Myers KP, Sclafani A. Dev Psychobiol. 2006;48:380-8.

O’Doherty J, Rolls ET, Francis S, Bowtell R, McGlone F. J Neurophysiol. 2001;85:1315-21.

Pearce JM. Anim Learn Behav. 2002;30:73-95.

Pelchat ML, Rozin P. Appetite. 1982;3:341-51.

Piazza CC, Patel MR, Santana CM, Goh HL, Delia MD, Lancaster BM. J Appl Behav Anal. 2002;35:259-70.

Raynor HA, Epstein LH. Psychol Bull. 2001;127:325-41.

Rolls ET. Cereb Cortex. 2000;10:284-94.

Siep N, Roefs A, Roebroeck A, Havermans R, Bonte M, Jansen A. Behav Brain Res. 2009;198:149-58.

Small DM, Zald DH, Jones-Gotman M, Zatorre RJ, Pardo JV, Frey S, et al. NeuroReport. 1999;10:7-14.

Swinburn BA, Sacks G, Lo SK, Westerterp KR, Rush EC, Rosenbaum M, et al. Am J Clin Nutr. 2009;89:1723-8.

Visscher TLS, Kromhout D, Seidell JC. Int J Obes. 2002;26:1218-24.

Williams KE, Paul C, Pizzo B, Riegel K. Appetite. 2008;51:739-42.

Yeomans MR, Mobini S. J Exp Psychol Anim Behav Process. 2006;32:460-6.

Yeomans MR, Leitch M, Gould NJ, Mobini S. Physiol Behav. 2008;93:798-806.

Zellner DA, Rozin P, Aron M, Kulish C. Learn Motiv. 1983;14:338-50. 